\title{
The Adsorption of Reactive Blue 19 Dye onto Cucurbit[8]uril and Cucurbit[6]uril: An Experiment and Theoretical Study
}

\author{
Xiaomei Xie ${ }^{1,2}$, Xiaolei $\mathrm{Li}^{1,2}$, Hanhan luo ${ }^{1,2}$, Huijuan $\mathrm{Lu}^{1,2}$, Feifei Chen ${ }^{1,2}$, Wei Li ${ }^{1,2 *}$
}

${ }^{1}$ College of Chemistry and Chemical engineering, Wuhan Textile University, Wuhan, 430073,

China.

${ }^{2}$ Hubei Key Laboratory of Biomass Fiber and Eco-dyeing\&Finishing,Wuhan Textile University, 430073, China.

\section{Supplementary information}

Figure 1-1. Comparison of simulated and experimental spectrum

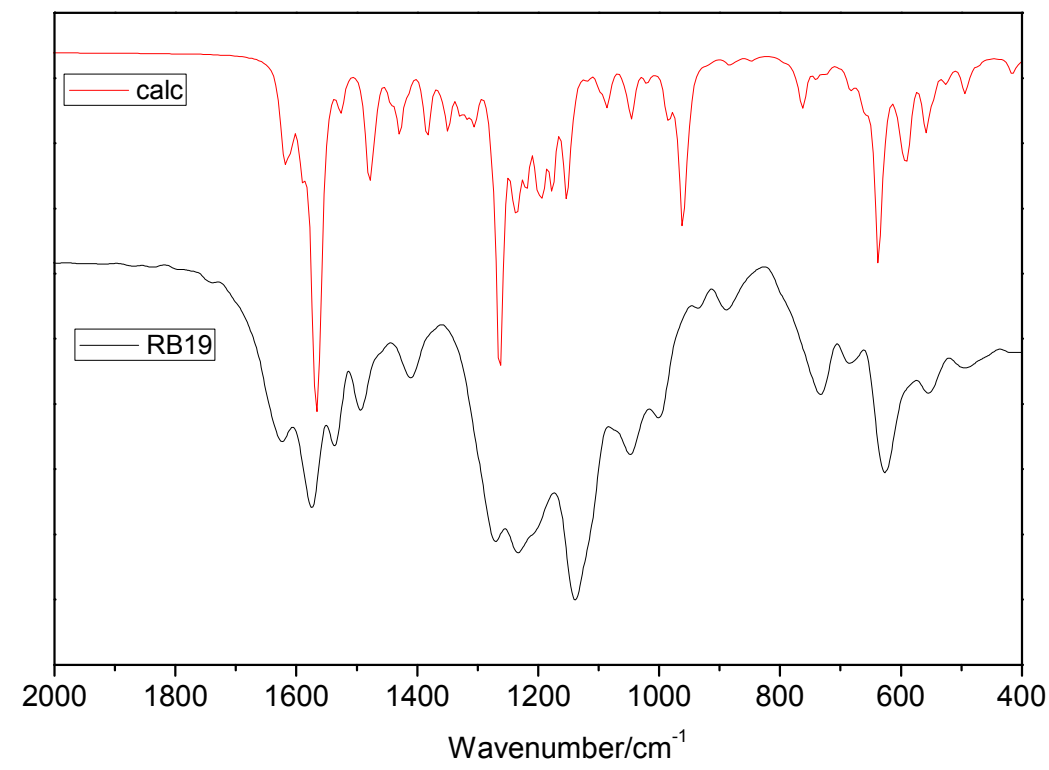

${ }^{*}$ Correspondence to: Wei Li, college of Chemistry and Chemical Engineering, Wuhan Textile University, Wuhan 430073, China. E-mail: liwei whu@sohu.com 

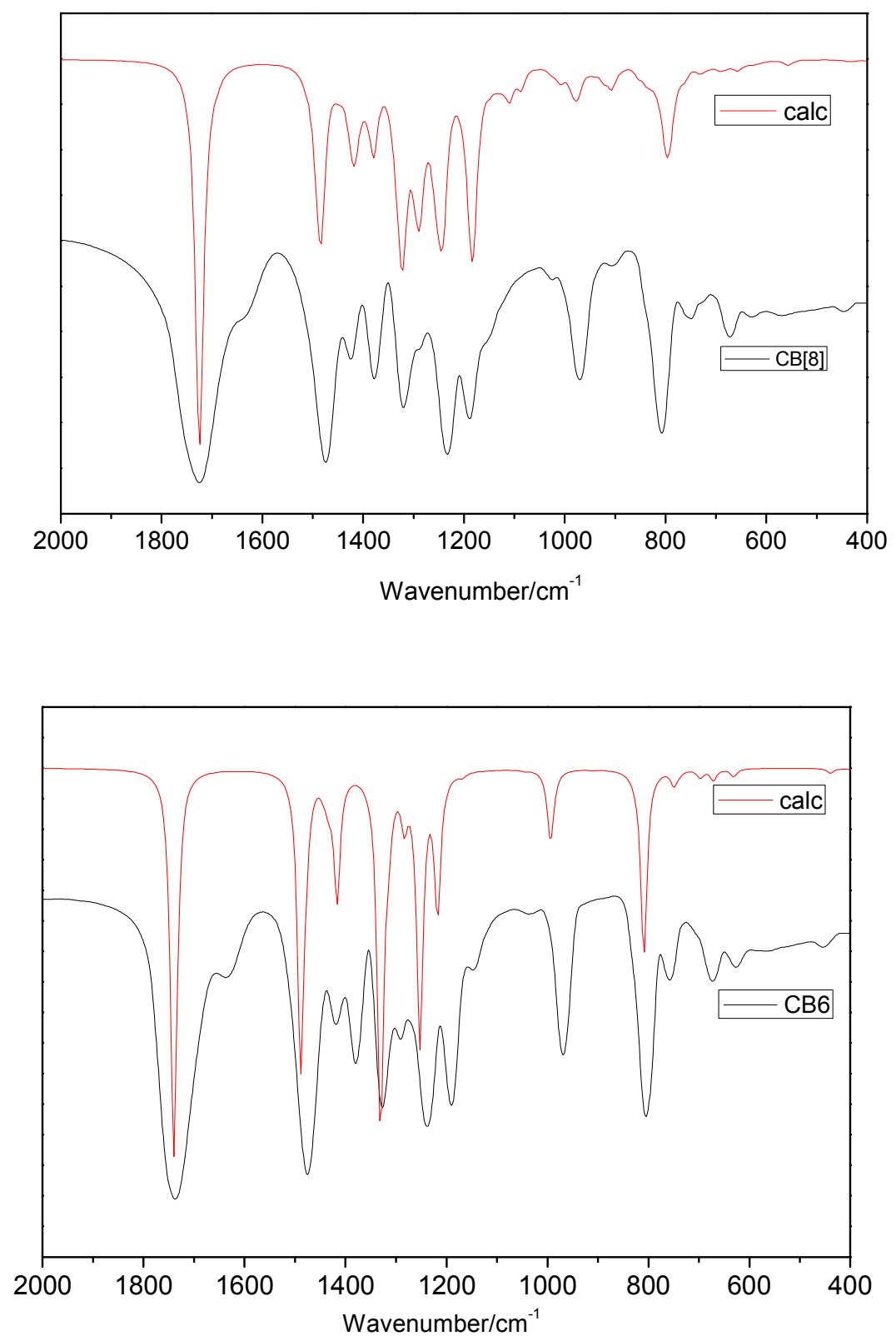

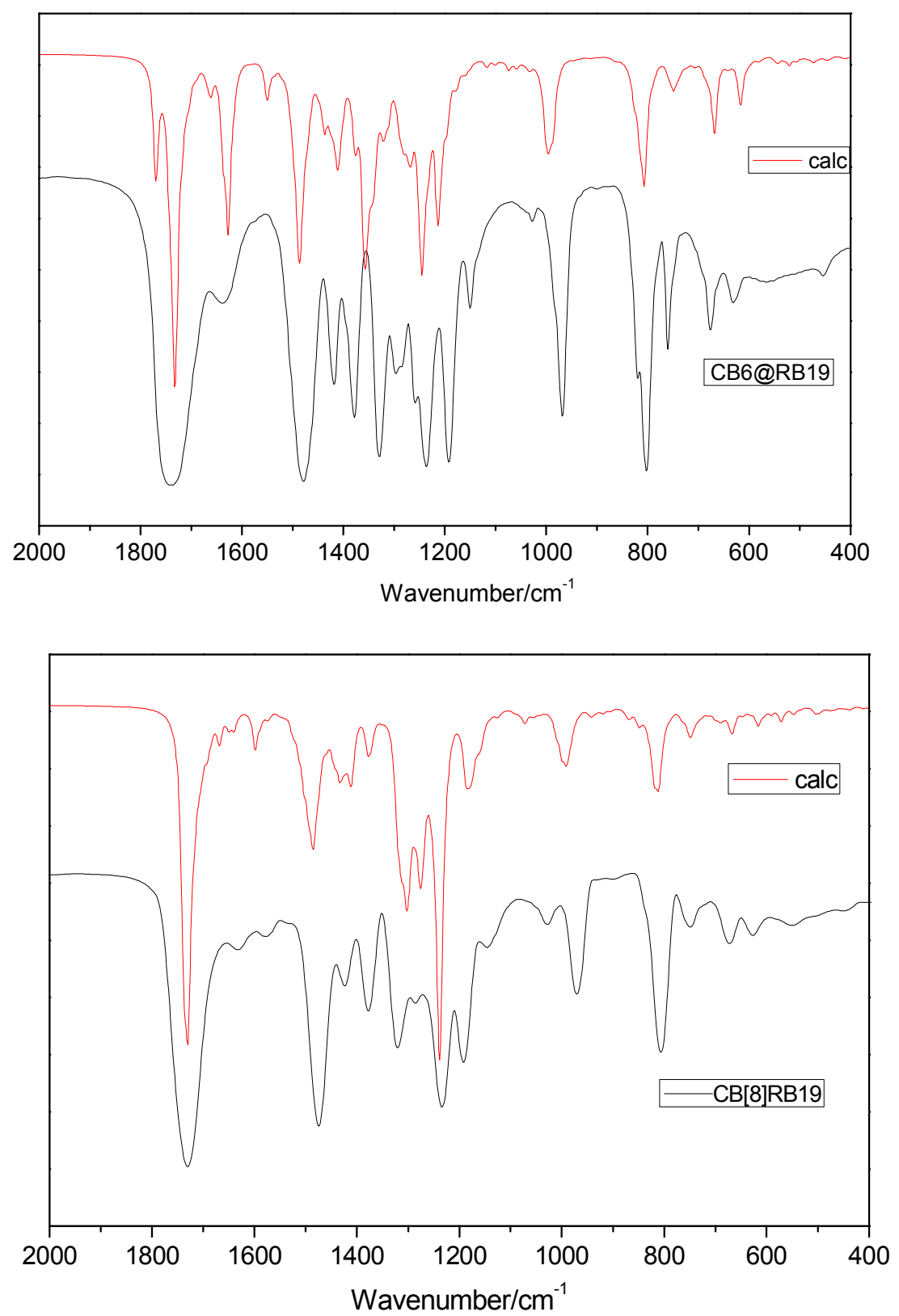
Table 1-1. Percentage Composition of The Lowest Unoccupied and Highest Occupied Orbitals Involving Electronic Transition of CB[8]@RB19 Inclusion Complex in Terms of CB[8] and RB19 Fragments

\begin{tabular}{cccc}
\hline orbital & \multicolumn{2}{c}{ contribution } & Property \\
\hline H-56 & RB19 & CB[8] & $\mathrm{p}$ \\
H-26 & 85 & 88 & $\pi$ \\
H-8 & 8 & 15 & $\mathrm{p}$ \\
H-1 & 99 & 92 & $\pi$ \\
HOMO & 99 & 1 & $\pi$ \\
LUMO & 99 & 1 & $\pi^{*}$ \\
L+3 & 96 & 1 & $\pi^{*}$ \\
L +5 & 23 & 4 & $\mathrm{p}$ \\
\hline
\end{tabular}

